Manifeste und Proklamationen

der europäischen Avantgarde (1909-1938) 


\title{
Manifeste und Proklamationen der europäischen Avantgarde (1909-1938)
}

\author{
Herausgegeben von Wolfgang Asholt \\ und Walter Fähnders
}


Die Deutsche Bibliothek - CIP-Einheitsaufnahme

Manifeste und Proklamationen der europäischen Avantgarde :

(1909 - 1938) / hrsg. von Wolfgang Asholt und Walter Fähnders.

- Stuttgart ; Weimar : Metzler, 1995

ISBN 978-3-476-01322-4

NE: Asholt, Wolfgang [Hrsg.]

ISBN 978-3-476-01322-4

ISBN 978-3-476-03610-0 (eBook)

DOI 10.1007/978-3-476-03610-0

Dieses Werk einschließlich aller seiner Teile ist urheberrechtlich geschützt. Jede Verwertung außerhalb der engen Grenzen des Urheberrechtsgesetzes ist ohne Zustimmung des Verlages unzulässig und strafbar. Das gilt insbesondere für Vervielfältigungen, Übersetzungen, Mikroverfilmungen und die Einspeicherung und Verarbeitung in elektronischen Systemen.

(C) 1995 Springer-Verlag GmbH Deutschland

Ursprünglich erschienen bei J. B. Metzlersche Verlagsbuchhandlung und Carl Ernst Poeschel Verlag GmbH in Stuttgart 1995 


\section{Inhalt}

Einleitung XV

Teil I:

Der futuristische Aufbruch der Avantgarde (1909-1916)

1

1909

F. T. Marinetti: Gründung und Manifest des Futurismus $\ldots \ldots \ldots \ldots \ldots \ldots$

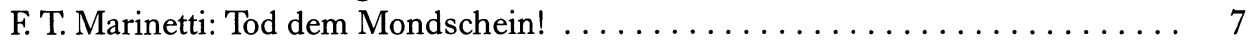

1910

U. Boccioni/C. D. Carrà/L. Russolo u. a.: Manifest der futuristischen Maler . . . . 11

U. Boccioni/C. D. Carrà/L. Russolo u.a.: Die Futuristische Malerei. Technisches Manifest .............................. 13

L. Altomare/U. Boccioni/A. Bonzagni u.a.: Manifest gegen das passatistische

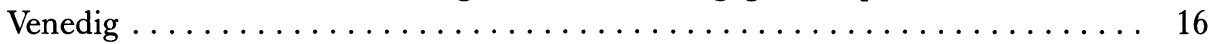

Tristán: Futuristische Proklamation an die Spanier . . . . . . . . . . 17

B. Pratella: Manifest der futuristischen Musiker $\ldots \ldots \ldots \ldots \ldots \ldots \ldots \ldots$

1911

F. T. Marinetti/Die futuristischen Dichter/Die futuristischen Maler u.a.: Manifest der futuristischen Bühnendichter . . . . . . . . . . . . . . . . . 19

F. T. Marinetti: Zweites politisches Manifest $\ldots \ldots \ldots \ldots \ldots \ldots \ldots \ldots \ldots \ldots$

1912

V. de Saint-Point: Manifest der futuristischen Frau. Antwort an F. T. Marinetti . . . 21

U. Boccioni: Die futuristische Bildhauerkunst ............... 23

F. T. Marinetti: Technisches Manifest der futuristischen Literatur . . . . . . . . . . 24 
D. Burljuk/A. Kručonych/V. Majakovskij u.a.: Eine Ohrfeige dem öffentlichen

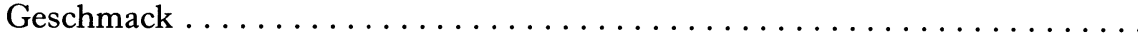

1913

V. de Saint-Point: Futuristisches Manifest der Wollust . . . . . . . . . . . . . 29

L. Russolo: Die Geräuschkunst . . . . . . . . . . . . . . . . . . . . . 30

A. Döblin: Futuristische Worttechnik. Offener Brief an F. T. Marinetti $\ldots \ldots \ldots \ldots 32$

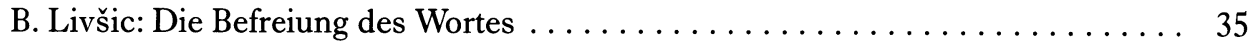

Anonym: Manifest der amorphistischen Schule $\ldots \ldots \ldots \ldots \ldots \ldots \ldots \ldots$

F. T. Marinetti: Zerstörung der Syntax - Drahtlose Phantasie - Befreite Worte . . . 39

G. Apollinaire: Die futuristische Antitradition [Faksimile] . . . . . . . . . . . 44

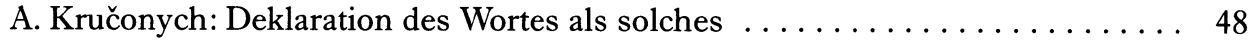

A.-F. Mac Delmarle: Futuristisches Manifest gegen Montmartre . . . . . . . . . . . . 49

M. Matjušin/ A. Kručonych/K. Malevič: Manifest des Ersten allrussischen

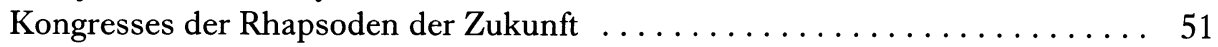

T. Bogomazov/ N. Gončarova/ K. Zdanevič u.a.: Rayonisten und Zukünftler . . . . 52

St. K. Neumann: Offene Fenster $\ldots \ldots \ldots \ldots \ldots \ldots \ldots \ldots \ldots \ldots \ldots \ldots$

C. D. Carrà: Die Malerei der Töne, Geräusche und Gerüche . . . . . . . . . . . 56

O. Kanehl: Futurismus. Ein nüchternes Manifest $\ldots \ldots \ldots \ldots \ldots \ldots \ldots \ldots$

F. T. Marinetti: Das Varieté . . . . . . . . . . . . . . . . . . . . . 60

A. Stech: Aufruf zum Manifestantismus $\ldots \ldots \ldots \ldots \ldots \ldots \ldots \ldots \ldots$

F. T. Marinetti/ U. Boccioni/ C. Carrà u.a.: Politisches Programm des Futurismus . 65

A. Palazzeschi: Der Gegenschmerz $\ldots \ldots \ldots \ldots \ldots \ldots \ldots \ldots \ldots \ldots \ldots \ldots 6$

M. Larionov/ I. Zdanevič: Warum wir uns bemalen. Manifest der Futuristen . . . . 67

A. Kručonych/ V. Chlebnikov: Das Wort als solches . . . . . . . . . . . . . . 69

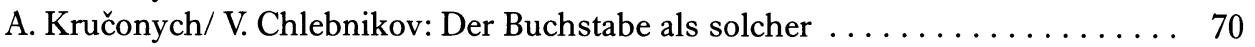

D. Burljuk/ E. Guro/ N. Burljuk u. a.: Richterteich . . . . . . . . . . . . . . 71

1914

G. Jakulov/ B. Livšic/ A. Lurjé: Wir und der Westen. (Plakat No. 1) . . . . . . . 72

D. Burljuk/ A. Kručonych/ B. Livšic u. a.: Schert euch zum Teufel . . . . . . . . 73

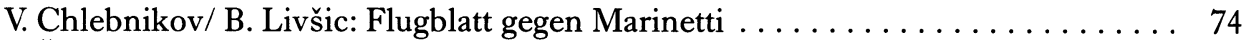

V. Šeršenevič: Deklaration über das futuristische Theater . . . . . . . . . . . . . . 75

F. T. Marinetti/ C. R. W. Nevinson: Vitale Englische Kunst . . . . . . . . . . . 77

Vortex: Manifest .............................. 79

R. Aldington/ J. Arbuthnot/ L. Atkinson u. a.: Manifest . . . . . . . . . . . 81

W. Lewis: Das Melodrama der Modernität . . . . . . . . . . . . . . . . . . . . 82

M. Loy: Futuristische Aphorismen $\ldots \ldots \ldots \ldots \ldots \ldots \ldots \ldots \ldots \ldots \ldots$

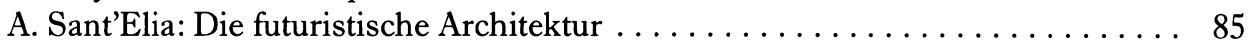

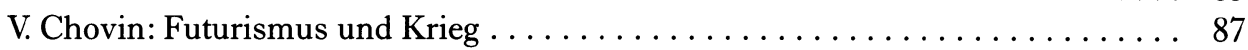

F. T. Marinetti/ U. Boccioni/ C. Carrà u.a.: Futuristische Synthese des Krieges

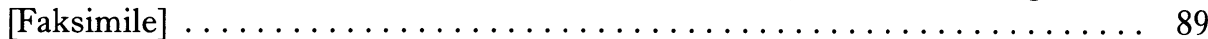

N. Burljuk/ D. Burljuk: Poetische Prinzipien $\ldots \ldots \ldots \ldots \ldots \ldots \ldots \ldots \ldots \ldots$

1915

F. T. Marinetti/ E. Settimelli/ B. Corra: Das futuristische synthetische Theater . . . 92

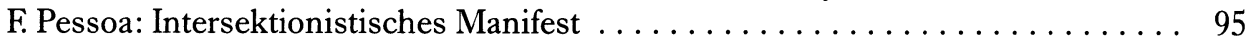


H. Ball/ R. Huelsenbeck: Ein literarisches Manifest $\ldots \ldots \ldots \ldots \ldots \ldots \ldots \ldots$

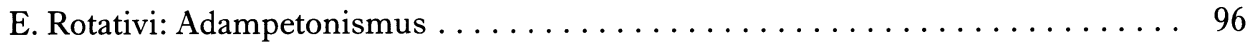

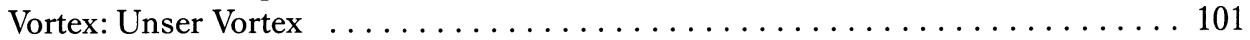

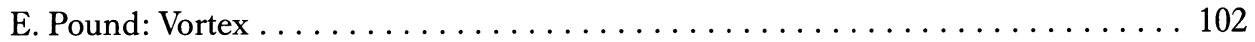

A. Undo: Der Impertinentismus. Ein Manifest . . . . . . . . . . . . . . . . 104

I. Puni/ X. Boguslawskaja/ K. Malevič u.a.: Die suprematistischen Manifeste der »Letzten futuristischen Bilderausstellung $0.10 \ll \ldots \ldots \ldots \ldots \ldots \ldots \ldots \ldots \ldots$

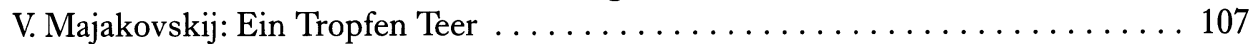

1916

P. Iašvili: Unser erstes Wort. Manifest . . . . . . . . . . . . . . . . . 109

Die Blauen Hörner: An unsere gelben Feinde. . . . . . . . . . . . . . 111

B. Corra/ A. Ginanni/ R. Chiti u.a.: Die futuristische Wissenschaft (antideutsch abenteuerlich - launenhaft - sicherheitsallergisch - trunken vom

Unbekannten). Futuristisches Manifest . . . . . . . . . . . . . . . . 112

St. Wronski: Die Äternisten. Erste Proklamation des Äternismus . . . . . . . . . . 113

J. de Almada-Negreiros: Anti-Dantas-Manifest und so weiter . . . . . . . . . 114

R. Huelsenbeck: Erklärung. Vorgetragen im Cabaret Voltaire, im Frühjahr 1916. . . 117

\section{Teil II: \\ Zwischen >Dada $<$ und $>$ Revolution` (1916-1920) 119}

H. Ball: Eröffnungs-Manifest. 1. Dada-Abend, Zürich, 14. Juli 1916 . . . . . . . . 121

T. Tzara: Manifest des Herrn Antipyrine . . . . . . . . . . . . . . . 122

V. Chlebnikov/ M. Sinjakova/ Božidar u.a.: Trompete der Marsianer . . . . . . . 123

F. T. Marinetti/ B. Corra/ E. Settimelli u. a.: Der futuristische Film . . . . . . . 123

1917

O. Brik/ L. Bruni/ V. Ermolaeva u. a.: Auf zur Revolution . . . . . . . . . . . . 126

V. Chlebnikov/ G. Petnikov: Aufruf der Vorsitzenden des Erdballs . . . . . . . . . 127

J. de Almada-Negreiros: Futuristisches Ultimatum an die portugiesischen

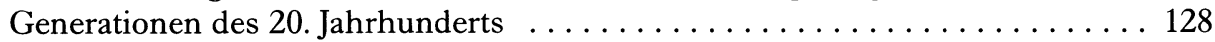

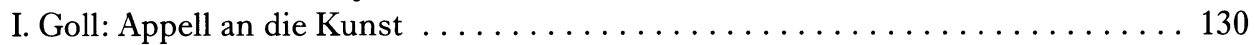

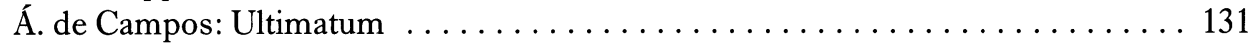

J. Torres-Garcia: Evolutions-Kunst (In der Art eines Manifests) . . . . . . . 135

1918

M. Poal Arregall: Manifest an die Weiblichkeit $\ldots \ldots \ldots \ldots \ldots \ldots \ldots \ldots \ldots$

R. Huelsenbeck: Dadarede, gehalten in der Galerie Neumann, Berlin, Kurfürstendamm, am 18. Februar 1918 . . . . . . . . . . . . . . . . . . . . . . 139

V. Majakovskij/ D. Burljuk/ V. Kamenskij: Dekret Nr. 1

über die Demokratisierung der Künste 
W. Serner: Letzte Lockerung manifest . ..................... 141

T. Tzara/ F. Jung/ G. Grosz u. a.: Dadaistisches Manifest [Faksimile] . . . . . . . . . 145

R. Hausmann: Manifest von der Gesetzmäßigkeit des Lautes . . . . . . . . . . . 148

T. Tzara: Manifest Dada 1918 . . . . . . . . . . . . . . . . . . . . . . . . . 149

G. Balla: Das Manifest der Farbe ........................... 155

Th. van Doesburg/ R. van't Hoff/ V. Huszár u.a.: Manifest I von »Der Stil« 1918 .. 156

Anonym: Gegen den Besitz . . . . . . . . . . . . . . . . . . . . . . . 157

Das Redaktionskollegium: Dieses Buch muß jeder lesen! . . . . . . . . . . . . 159

N. Altmann: 'Futurismus` und proletarische Kunst. $1918 \ldots \ldots \ldots \ldots \ldots \ldots .60$

1919

M. Janco: Die Kunst will und muß wieder zum Leben zurückkehren... . . . . . . 162

J. Baader/ R. Hausmann/ T. Tzara u.a.: Dadaisten gegen Weimar [Faksimile] ..... 163

X. Bóveda/ C. A. Comet/ G. de Torre u. a.: Ultra. Ein Manifest der literarischen Jugend ....................................... 164

C. Einstein: An die Geistigen! . . . . . . . . . . . . . . . . . . . . . . 164

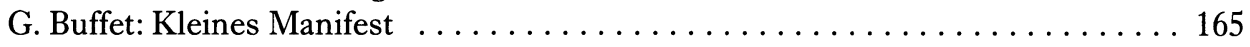

S. Barta/ I. Hevesi/ M. Kahána u. a.: Revolutionäre! . . . . . . . . . . . . . . . . 166

H. Richter: Gegen Ohne Für Dada . . . . . . . . . . . . . . . . . . . . . . 168

V. Chlebnikov: An die Maler der Welt $\ldots \ldots \ldots \ldots \ldots \ldots \ldots \ldots \ldots \ldots . \ldots \ldots$

R. Hausmann: Pamphlet gegen die Weimarische Lebensauffassung ........ 171

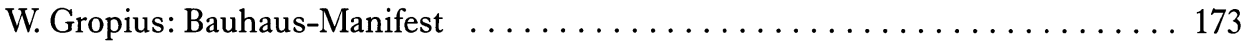

H. Arp/ F. Baumann/ V. Eggeling u.a.: Manifest radikaler Künstler . . . . . . . . . 174

F. Picabia: Anderes kleines Manifest . . . . . . . . . . . . . . . . . . . 174

R. Hausmann/ R. Huelsenbeck/ J. Golyscheff: Was ist der Dadaismus und was will er in Deutschland? . . . . . . . . . . . . . . . . . . . . . . . . . . . . . . . 175

Zentralamt des Dadaismus: Legen Sie Ihr Geld in dada an! ............ 176

I. Vando-Villar: Ultraistisches Manifest . . . . . . . . . . . . . . . . . 177

J. Molzahn: Das Manifest des absoluten Expressionismus. ............... 177

K. Schwitters: An alle Bühnen der Welt . . . . . . . . . . . . . . . . . . . . . 179

F. T. Marinetti: Jenseits vom Kommunismus . . . . . . . . . . . . . . . . 181

R. Hausmann: Der deutsche Spießer ärgert sich [Faksimile] $\ldots \ldots \ldots \ldots \ldots \ldots . \ldots \ldots$

G. Milev: Das Fragment . . . . . . . . . . . . . . . . . . . . . . . . . . . . . 185

K. Malewitsch: Über die Poesie . . . . . . . . . . . . . . . . . . . . . . . . . . 185

1920

Anonym: Manifest der Dada-Bewegung $\ldots \ldots \ldots \ldots \ldots \ldots \ldots \ldots \ldots \ldots \ldots \ldots \ldots$

W. C. Arensberg: Dada ist amerikanisch $\ldots \ldots \ldots \ldots \ldots \ldots \ldots \ldots \ldots \ldots \ldots \ldots \ldots$

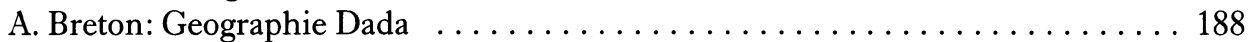

G. Ribemont-Dessaignes: An das Publikum . . . . . . . . . . . . . . . . . 189

C. Arnauld: Dada-Sonnenschirm . . . . . . . . . . . . . . . . . . . . . . 189

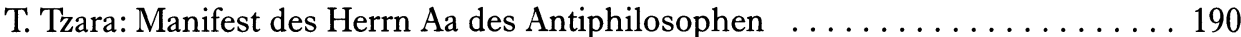

F. Picabia: Dada Manifest .................................. 191

F. Picabia: Manifeste Cannibale Dada . . . . . . . . . . . . . . . . . . . . 192

P. Dermée: Was ist Dada! . . . . . . . . . . . . . . . . . . . . . . . . . . 193 


\section{Teil III:}

\section{Die Zeit der Ismen (1920-1924)}

195

T. Tzara: Proklamation ohne Anspruch . . . . . . . . . . . . . . . . . . 197

L. Kassák: An die Künstler aller Länder! . . . . . . . . . . . . . . . . . . . . . . 197

H. Hoerle: Dilettanten erhebt euch... [Faksimile] . . . . . . . . . . . . . 200

d'Adamax: Adamismus . . . . . . . . . . . . . . . . . . . . . 201

Th. van Doesburg/ P. Mondriaan/ A. Kok: Kundgebung II des »Stij1« 1920.

Die Wortkunst . . . . . . . . . . . . . . . . . . . . . . . . . . 201

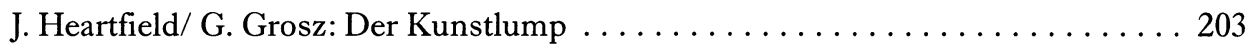

N. Gabo/ N. Pevsner: Realistisches Manifest . . . . . . . . . . . . . . . . 206

A. Rodschenko/ W. Stepanowa: Produktivistenmanifest . . . . . . . . . . 210

J. Martín/ Z. Guimel: Erstes Manifest sAgús . . . . . . . . . . . . . . . . . . 212

A. Stern/ A. Wat: Die Primitivisten an die Völker der Welt und an die Polen . . . . 213

P. van Ostaijen: Et Voilà. Ein Manifest zur Einführung . . . . . . . . . . . . . 214

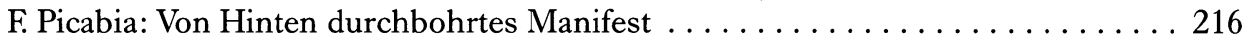

Club Dada: Eine Erklärung des Club Dada . . . . . . . . . . . . . . . . . . 217

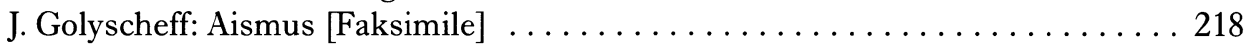

1921

F. T. Marinetti: Der Taktilismus. Futuristisches Manifest . . . . . . . . . . . . 219

E. Varèse/ T. Tzara/ Ph. Soupault u.a.: Dada hebt alles auf . . . . . . . . . . 223

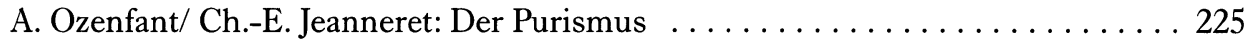

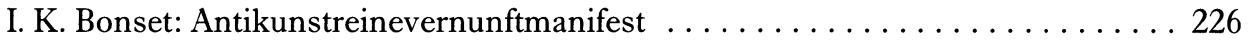

K. Medunezki/ W. Stenberg/ G. Stenberg: Die Konstruktivisten rufen die Welt . . 228

A. Rodtschenko: Losungen . . . . . . . . . . . . . . . . . . . . . . 229

J. Sureda/ F. Bonanova/ J. Alomar u. a.: Manifest des Ultra . . . . . . . . . . . . 230

R. Hausmann: PRÉsentismus. Gegen den Puffkeismus der teutschen Seele . . . . 231

S. Barta: Der Mensch mit dem grünen Kopf oder Manifest einer aktiven Leiche... 233

B. Jasieński: Manifest in Sachen futuristische Dichtung . . . . . . . . . . . . 237

Schöpferisches Büro der Nitschewoki: Rußlands Nitschewoki -

Dada des Ostens . . . . . . . . . . . . . . . . . . . . . . . . . . . . 240

B. Jasieński: An das polnische Volk.

Manifest in Sachen der sofortigen Futurisierung des Lebens . . . . . . . . . 240

T. Czyzewski: Von der Maschine zu den Tieren . . . . . . . . . . . . 243

T. Czyzewski: Über "grünes Auge« und über meine Malerei

(Autokritik - Autoreklame) . . . . . . . . . . . . . . . . . . . . . . . 244

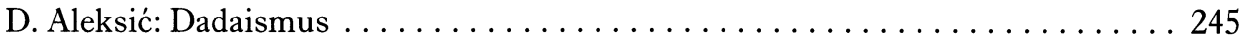

J. L. Borges: Anatomie meines Ultra $\ldots \ldots \ldots \ldots \ldots \ldots \ldots \ldots \ldots \ldots \ldots \ldots \ldots$

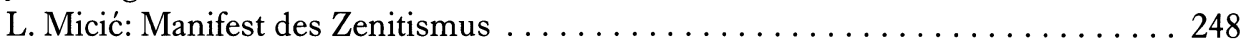

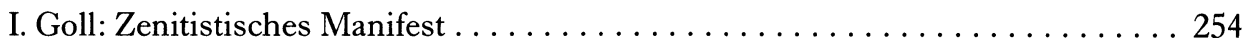

De Stijl: Manifest III. Zur neuen Weltgestaltung $\ldots \ldots \ldots \ldots \ldots \ldots \ldots \ldots \ldots$

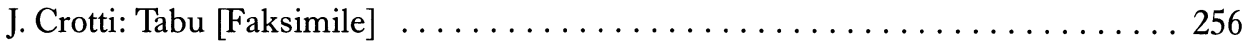

R. Hausmann/ H. Arp/ I. Puni: Aufruf zur elementaren Kunst. . . . . . . . . . . 257

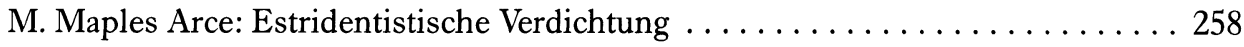




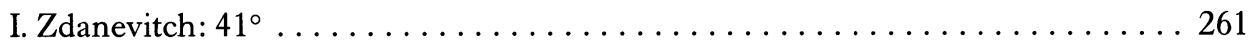

J. L. Borges/ G. de Torre/ E. Gonzáles Lanuza u.a.: Mauer-Prisma Nr. 1.

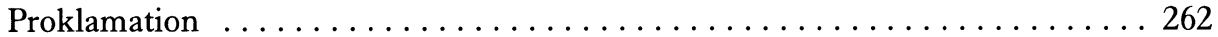

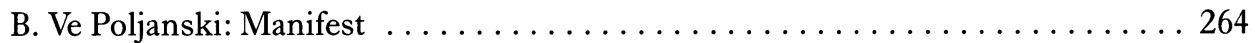

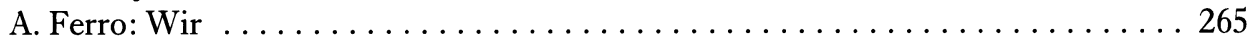

A. Kručonych: Deklaration der sa-umnischen Sprache . . . . . . . . . . . 267

M. Duchánski-Blaga: Manifest (Fest-mani) . . . . . . . . . . . . . . . . 269

1922

J. L. Borges/ G. de Torre/ E. González Lanuza u.a.: Mauer-Prisma Nr. 2 . . . . . 270

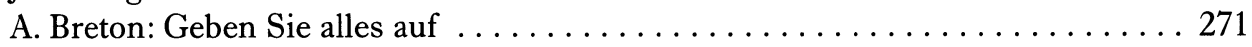

St. Kubicki/ O. Freundlich/ T. Remy u.a.: Zweites Manifest der Kommune . . . . . 273

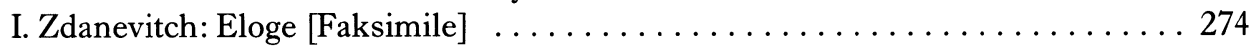

De Stijl: Schöpferische Forderungen von $»$ De Stijl $\ldots \ldots \ldots \ldots \ldots \ldots \ldots \ldots \ldots 275$

Th. van Doesburg/ El Lissitzky/ H. Richter: Erklärung

der internationalen Fraktion der Konstruktivisten

des ersten internationalen Kongresses der fortschrittlichen Künstler . . . . . . 275

I. Puni/ K. Zalit/ A. Dzirkal: Proklamation der Gruppe ’Synthès‘. . . . . . . . . 276

E. Lissitzky/ I. Ehrenburg: Deklaration an den ersten Kongreß fortschrittlicher

Künstler, Düsseldorf . . . . . . . . . . . . . . . . . . . . . . . . . . 277

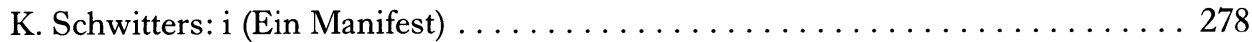

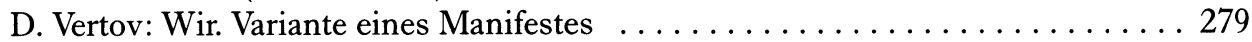

Th. van Doesburg/ E. Lissitzky/ H. Richter u.a.: K. I. Konstruktivistische

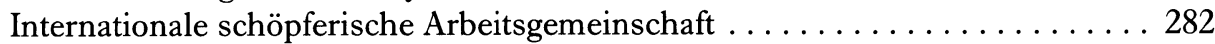

T. L. Batista/ V. Palés Matos: Euphoristisches Manifest . . . . . . . . . . . 283

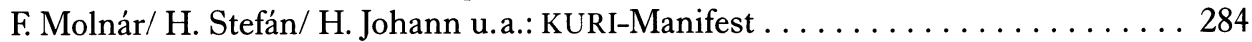

Z. Kemény/ L. Moholy-Nagy: Dynamisch-konstruktives Kraftsystem . . . . . . . 287

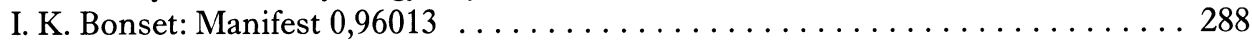

V. Servranckx/ V. Magritte: Über die Malerei . . . . . . . . . . . . . . 288

1923

M. Maples Arce/ G. List Arzubide/ S. Gallardo u.a.: Estridentistisches Manifest . . 289

E. Prampolini/ I. Pannaggi/ V. Paladini: Die mechanische Kunst . . . . . . . . . . 291

V. Palés Matos/ Th. L. Batista: Zweites Euphoristisches Manifest.

Den Dichtern Amerikas! . . . . . . . . . . . . . . . . . . . . . . . . . . . . . . . 293

Kinoki: An die Kinematographisten . . . . . . . . . . . . . . . . . . 294

Th. van Doesburg: Charakteristik des Dadaismus . . . . . . . . . . . . . . 294

N. Aseev/ B. Arvatov/ O. Brik u. a.: Programm. Wofür kämpft »Lef«? . . . . . . . . 296

Th. van Doesburg/ K. Schwitters/ H. Arp. u.a.: Manifest Proletkunst . . . . . . . . . 298

V. Eggeling/ R. Hausmann: Zweite präsentistische Deklaration.

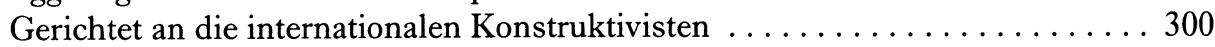

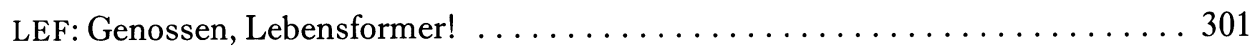

P. N. Filonow: Deklaration des $»$ Welterblühens« $\ldots \ldots \ldots \ldots \ldots \ldots \ldots \ldots \ldots \ldots 30 \ldots \ldots$

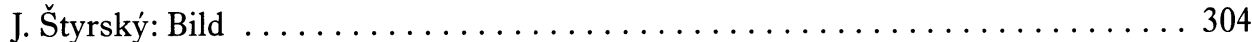

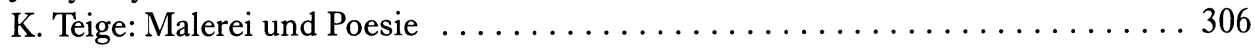

P. Mondrian: Muß Malerei der Architektur gegenüber als minderwertig gelten? . . 308

H. Werkman: Anfang der violetten Jahreszeit . . . . . . . . . . . . . . . 309 
1924

O. de Andrade: Manifest der Pau-Brasil-Dichtung . . . . . . . . . . . . . . . . . 309

K. Malewitsch: Suprematistisches Manifest Unowis . . . . . . . . . . . 313

Gruppe >Martín Fierro<, Buenos Aires: Martín Fierro Manifest . . . . . . . . . 315

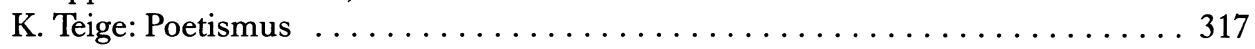

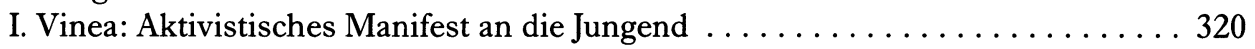

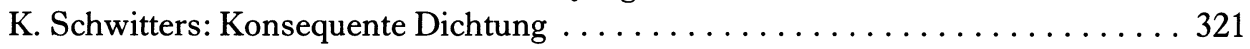

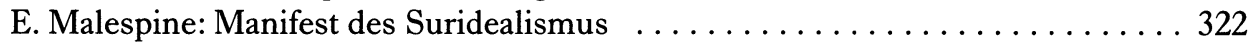

M. Szczuka: Was ist Konstruktivismus . . . . . . . . . . . . . . . . . 324

\section{Teil IV:}

Im Zeichen des Surrealismus (1924-1938)

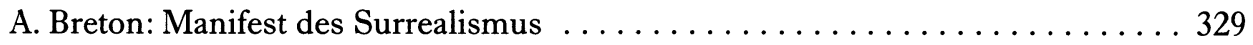

Y. Goll: Manifest des Surrealismus . . . . . . . . . . . . . . . . . . . 332

I. Voronca: Aviogramm . . . . . . . . . . . . . . . . . . . . . . 334

Die Redaktion von »La Révolution surréaliste«:

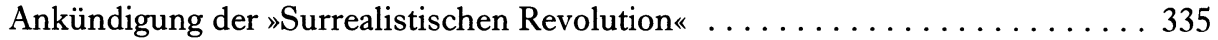

F. Picabia: Dadaismus, Instantaneismus. 391 [Faksimile] . . . . . . . . . 336

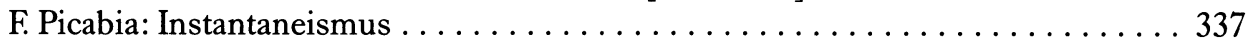

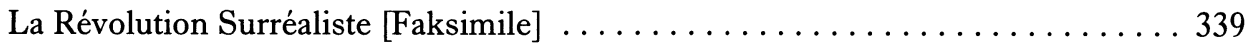

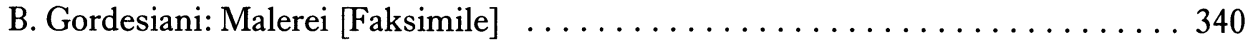

1925

Die surrealistische Gruppe, Paris: Öffnet die Gefängnisse, entlaßt die Armee . . . . 341

L. Aragon: Moral - Wissenschaft: Es steht Euch frei! . . . . . . . . . . . . . . 342

L. Aragon/ A. Artaud/ J. Baron u.a.: Erklärung des Büros für surrealistische

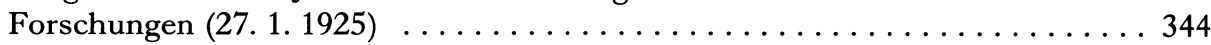

M. Seuphor: Manifest-Konferenz über das Unmögliche . . . . . . . . . . . . 345

A. Artaud: Die Tätigkeit des Büros für surrealistische Forschungen . . . . . . . 346

C. Goemans/ M. Lecomte/ P. Nougé: Um Abstand zu halten . . . . . . . . . . . . . . 348

A. Breton: Warum ich die Leitung der 'Surrealistischen Revolution ‘ übernehme . . 349

G. Altmann/ G. Aucouturier/ J. Bernier u.a.: Zunächst und immer Revolution! . . 352

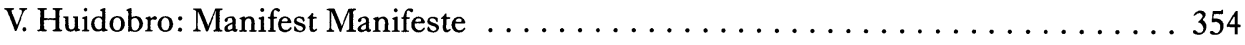

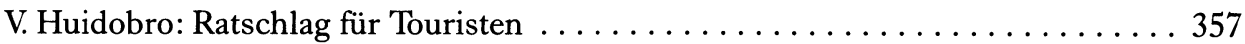

L. Micić: Manifest an die Barbaren des Geistes und Denkens auf allen Kontinenten . . . . . . . . . . . . . . . . . . . . . . . . . . . . . . . . 357

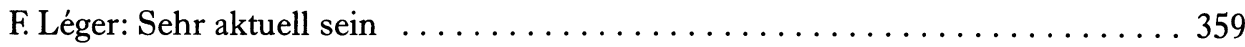

I. Voronca: Surrealismus und Integralismus $\ldots \ldots \ldots \ldots \ldots \ldots \ldots$

1926

C. Vallejo: Neue Poesie . . . . . . . . . . . . . . . . . . . . . . . . 361

A. Artaud: Manifest für ein gescheitertes Theater $\ldots \ldots \ldots \ldots \ldots \ldots \ldots \ldots 2$

J. C. Mariategui: Präsentation von Amauta . . . . . . . . . . . . . 364 
1927

Anonym: manifest nummer 1 der gewerkschaft der intellektuellen arbeiter und

künstler von kuba . . . . . . . . . . . . . . . . . . . . . . . 366

S. Gasch: Krieg dem Avantgardismus! . . . . . . . . . . . . . . . . . . . . 367

M. Alexandre/ L. Aragon/ H. Arp u. a.: Hands Off Love . . . . . . . . . . . . . . . . 367

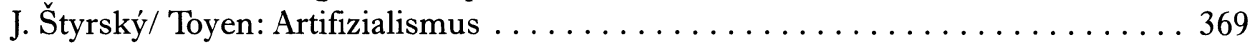

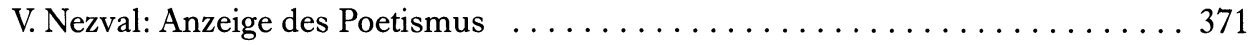

1928

OBERIU: Manifest. . . . . . . . . . . . . . . . . . . . . 372

S. Dalí/ L. Montanyá/ S. Gasch: Katalanisches Manifest gegen die Kunst.

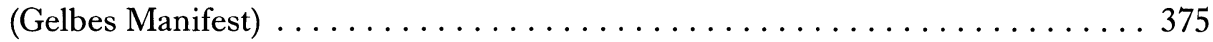

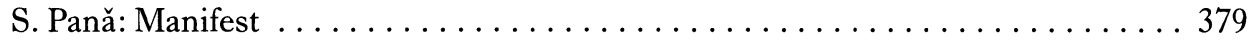

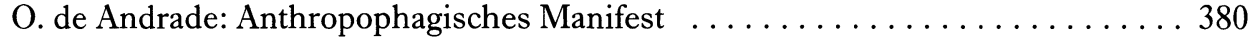

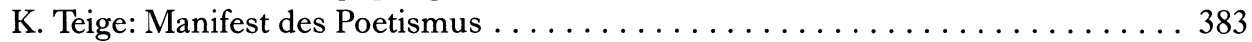

S. M. Eisenstein/ W. I. Pudowkin/ G. W. Alexandrow: Manifest zum Tonfilm . . . . 388

Anonym: Feuerträger . . . . . . . . . . . . . . . . . . 390

1929

S. Dalí: In dem Moment... . . . . . . . . . . . . . . . . . . . . . . 390

A. Breton: Zweites Manifest des Surrealismus . . . . . . . . . . . . . . . . 391

1930

M. A. Alexandre/ Aragon/ L. Buñuel u.a.: Zweite Ankündigung zum

"Zweiten Manifest des Surrealismus" . . . . . . . . . . . . . . . . . . . . . . . . 394

A. Vučo/ D. Jovanović/ Đ. Matić u. a.: Wer sind die dreizehn Surrealisten? . . . . . 395

O. Carlsund/ Th. van Doesburg/ J. Hélion u. a.: Manifest der konkreten Kunst . . 396

Die surrealistische Gruppe, Paris: Frage - Antwort. Telegramm nach Moskau . . . 397

P. Eluard: Die Liebe und die Entfremdung . . . . . . . . . . . . . . . . . . . 397

1931

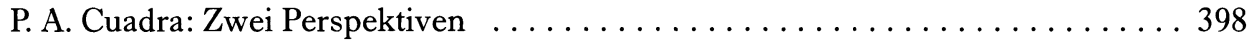

Die surrealistische Gruppe, Paris: Es gab eine Umfrage von Marinetti... . . . . . . 399

1932

H. Arp/ S. Beckett/ C. Einstein u. a.: Dichtung ist vertikal . . . . . . . . . 400

A. Artaud: Das Theater der Grausamkeit. (Erstes Manifest) . . . . . . . . . . . . . 401

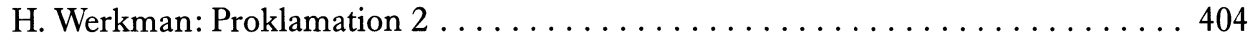

A. Galdikas/ A. Gudaitis/ Jonynas u.a. (Gruppe »Ars «): Manifest . . . . . . . . 405

1933

A. Artaud: Das Theater der Grausamkeit. (Zweites Manifest) . . . . . . . . . . 406

Die Redaktion der `Gaceta de arte $:$ 7. manifest. thema: der neue geist . . . . . . . . 409

Die Redaktion der `Gaceta de arte : 9. manifest. thema: die republik

und die ästhetik . . . . . . . . . . . . . . . . . . . . . . . . . . . . . 410 
1935

K. Biebl/ A. Breton/ B. Brouk u.a.: Proklamation des »1. Internationalen Bulletin des Surrealismus» . . . . . . . . . . . . . . . . . . . . . . . . . 412

R. Magritte/ E.-L.-T. Mesens, P. Nougé u.a.: Das Messer in der Wunde . . . . . . . 413

A. Breton/ S. Dali/ O. Dominguez u.a.: Als die Surrealisten noch Recht hatten . . 414

A. Acker/ P. Aimery/ G. Ambrosino u.a.: Gegenangriff.

Kampfbund der revolutionären Intellektuellen $\ldots \ldots \ldots \ldots \ldots \ldots \ldots \ldots$

V. Nezval: Warum ich Surrealist bin . . . . . . . . . . . . . . . . 417

1936

E. Agar/ A. Breton/ E. Burra u.a.: Erklärung anläßlich der surrealistischen

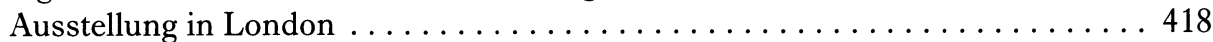

M. und M. Paz/ P. Rivet/ Alain u.a.: Appell an die Menschen . . . . . . . . . . 419

E. Pound: Die surrealistischen Feiglinge $\ldots \ldots \ldots \ldots \ldots \ldots \ldots \ldots \ldots \ldots \ldots \ldots$

1938

A. Breton/ D. Rivera [für L. Trotzki]: Für eine freie revolutionäre Kunst . . . . . 421 Die surrealistische Gruppe, Paris: Weder Euren Krieg noch Euren Frieden! . . . . 426

Nachweise 427

Länderverzeichnis der Manifeste 447

Auswahlbibliographie 455

Namenregister 469 


\section{Einleitung}

D

ie Avantgarde war eine Bewegung der Manifeste - kein Ismus, keine avantgardistische Zeitschrift, kaum ein Spektakel von Futuristen, Dadaisten oder Surrealisten, die ohne Manifeste ausgekommen wären. Im Manifest und anderen Formen des Proklamierens und Postulierens hat die shistorische Avantgardes der 10er, 20er und 30er Jahre auf authentische Weise ihre Ziele vermittelt, hat sie wie keine andere künstlerische Bewegung zuvor (und auch nicht danach) in diesem Genre ihr ureigenes Medium gefunden.

Zum einen konstituieren sich die Ismen durch Manifeste. Die Geburtsurkunden des italienischen Futurismus oder des französischen Surrealismus sind genau datierbar, und es bedurfte vom Aismus und Adampetonismus bis zu Dadaismus, Konstruktivismus, Surrealismus oder Zenitismus immer des Manifestes, um eine Bewegung zu kreieren, um Skandale zu provozieren oder sich abzugrenzen - nicht unbedingt auch des ästhetischen Werkes. (Ausnahmen finden sich am ehesten in der Bildenden Kunst, etwa dem Kubismus, der ohne Manifeste auskommt.)

Zum anderen sehen avantgardistische Autoren im Manifest einen exzellenten Weg der Selbstdarstellung; im Gruppen- oder Kollektivmanifest, aber noch im individuell und allein gezeichneten Aufruf präsentiert der Avantgardist seinen Anspruch, , Vorhut z zu sein, am konsequentesten - bis hinein in den Gestus einer »Ohrfeige für den öffentlichen Geschmack«, wie eines der Gründungsdokumente des russischen Futurismus lautet. Auch hier gibt es kaum einen avantgardistischen Künstler, der sich nicht am Manifesteschreiben oder -unterschreiben beteiligt hätte.

Zum dritten ist es das Besondere des Genres, das der Avantgarde die unglaublichsten Möglichkeiten zu bieten scheint, ihre Ziele zu bestimmen, ihr Treiben zu präsentieren und ihre Positionen zu definieren - unübersehbarer Hinweis auf ein abgrundtiefes Mißtrauen der Avantgarde gegenüber dem traditionellen Kunstwerk, gegenüber dem ,Werk ‘ mit seiner Aura und seiner besonderen Weise, eine 'Botschaft‘ zu übermitteln. Unter >Manifest ‘ firmiert dabei vieles: der ganz konventionelle Forderungskatalog ebenso wie das potenzierte 'Anti-Manifest‘, eine im dramatisch-erzählerischen Ton gehaltene Abrechnung mit dem Alten (»Tod dem Modschein«) ebenso wie spoetische Texte, die nichts Programmatisch-Diskursives an sich haben und nur durch ihren Titel behaupten, ein »Manifest« zu sein (so jedenfalls die Überschrift von Gabrielle Buffets Text); es gibt Manifeste, die ihre eigenen Forderungen selbst annullieren (wie das „Dadaistische Manifest« von 1918), und wir kennen ganze Serien von durchgezählten 
Manifesten, die Entwicklung und Kontinuität einer Avantgarde-Richtung markieren (wie bei den Manifesten von »de Stijl«, des französischen Surrealismus oder der "Gaceta de arte aus Tenerifa). Das avantgardistische Manifest ist eine äußerst praktikable und extrem soffene، Form.

Angesichts der Fülle von Manifesten, die sich in ihren inhaltlichen Forderungen ebenso grundsätzlich voneinander unterscheiden wie in ihrer jeweiligen Machart, fragt es sich, ob überhaupt an einem einheitlichen Begriff von Avantgarde festgehalten werden kann; ob nicht besser von 'Avantgarden' zu sprechen wäre (was einer Divergenz verschiedener >Vorhuten` gerecht würde) - Enzensberger hat frühzeitig bemerkt, daß »sich kein Standpunkt ausmachen läßt, von dem aus zu bestimmen wäre, was Avantgarde ist und was nicht «. Dennoch kann man, über konkurrierende Positionen der einzelnen Ismen hinaus, gerade am spezifisch avantgardistischen Genre des Manifestes die gemeinsame Basis eines 'Projekts Avantgarde‘ ausmachen. Jenseits aller Vielfalt und Widersprüchlichkeit avantgardistischer Schreibpraxis läßt sich in den Manifesten die Einheit der Avantgarde erkennen: ihre Utopie eines Ganzheitsentwurfs, die, um es mit Benjamin zu formulieren, beabsichtigt, "mit einer Praxis brechen zu wollen, die dem Publikum die literarischen Niederschläge einer bestimmten Existenzform vorlegt und diese Existenzform selber vorenthält.«Wenn sich damit nicht nur der Ort, sondern auch die Funktion von Kunst und Literatur ändert, wenn solcherart der Bereich von Kunst und Dichtung von innen her aufgesprengt wird, dann bildet das Manifest den brisantesten Explosivstoff. Es fragt sich, ob nicht gerade die für alle Avantgarde-Strömungen unverzichtbare Notwendigkeit, sich dieses Genres zu bedienen, völlig neue Hinweise auf die Spezifik der Avantgarde und einer allen Avantgarde-Richtungen gemeinsamen Teleologie darstellt. Dabei spielt die Frage, ob denn all das, was das avangardistische Manifest fordert, auch eingelöst worden ist - oder überhaupt eingelöst werden kann -, nicht die entscheidende Rolle; das Manifestieren selbst ist revolutionärer avantgardistischer Akt.

\section{Avantgarde und Manifestantismus}

Die Manifeste der Avantgarde stehen in der Kontinuität des künstlerischen Manifestantismus, wie ihn das 19. Jahrhundert hervorgebracht hat; aber zugleich brechen sie mit ihm. Proklamationen und Manifeste werden offenbar dann geschrieben, wenn das künstlerische >Werk` als Botschaft dem Autor nicht mehr auszureichen scheint und er über sein ästhetisches Produkt hinaus andere Weisen der Mitteilungen erprobt. Daß sich hierin ein irritiertes Verhältnis zum Publikum zeigt, liegt auf der Hand, und sicher konstituiert sich die Literatur der >Moderne‘ nicht zuletzt durch dieses sich stets selbst begleitende Programm-Konzert ihrer Autoren. Der Begriff 'Moderne‘ soll hier durchaus eng gezogen werden: Ansatzweise in der deutschen Frühromantik, deutlich seit der Modernität Baudelaires und Rimbauds, spätestens seit dem Naturalismus in Deutschland (der den Begriff für das deutsche Sprachgebiet erstmals einführt) begegnen uns jene Proklamationen und Manifeste, die im L'art pour l'art und Ästhetizismus der Jahrhundertwende gipfeln und die das Terrain für den avantgardistischen Umschlag allererst bereiten.

Dabei respektiert diese literarisch-künstlerische Moderne freilich noch problemlos die Trennung von Kunstwerk und Manifest. Gerade aufgrund ihrer Publikationsorte und ihrer Sprache, mit denen sie sich bewußt an ein größeres Publikum wenden, 
betonen die Manifeste der Moderne ihren Unterschied zum autonomen Kunstwerk, zu dem das Manifest sich eben nicht zählt; sein Eigenleben markiert auch den Status eines Notbehelfs. Es sei hier nur auf ein Manifest wie Jean Moréas’ „Der Symbolismus" (»Le Symbolisme«) aus dem Pariser »Figaro« vom 18.9. 1886 verwiesen, um dies zu verdeutlichen. - Auf der einen Seite steht also in der Moderne das 'populäre`, ästhetisch unspezifische Genre 'Manifest‘, auf der anderen das seigentliche‘ Kunstwerk, dessen hermetisch-elitärer Charakter durch die flankierenden Manifeste noch in besonderer Weise betont wird.

Die Avantgarde macht damit Schluß. Der Bruch erfolgt in dem Moment, als der Manifestantismus der Moderne in der desillusionierten Melancholie von Fin de siècle und Décadence sein vorläufiges Ende gefunden hat. Dieser Gipfelpunkt der Kunstautonomie wird, historisch gesehen, zur Voraussetzung des avantgardistischen Bruches: weiter als im Ästhetizismus konnte die Trennung von Kunst und Leben wahrlich nicht getrieben werden. Es bedurfte der »leeren Erwartungen des Fin de siècle« (H. R. Jauss), damit - beginnend mit der ersten Futuristischen Programmerklärung von 1909 - die Folge der sIsmen der 10er, 20er und 30er Jahre einsetzen konnte. Dementsprechend ließen sich die Manifeste der Avantgarde als extreme 'Vorhut festantismus der Moderne lesen.

Darin äußert sich freilich nicht mehr so sehr ein gestörtes, sondern ein neues Verhältnis zum Publikum. Die Manifeste sollen nicht mehr vom Kunstwerk geschieden werden, ihre Form verweist vielmehr darauf, daß sie sich an der Grenze zwischen Kunstwerk und außerkünstlerischer Realität ansiedeln, daß man den Status des autonomen Kunstwerks in Frage stellt und das Manifest eine Brücke von der Kunst zum Leben schlagen soll. Das Manifest der Avantgarde verläßt damit zumindest tendenziell die Ebene des traditionellen >Werkes`. Nun gilt dies für die Avantgarde insgesamt, und eine solche Einschätzung der Avantgarde würde vermeiden, im Zusammenhang mit der intendierten »Unmittelbarkeit der gesellschaftsverändernden Wirkung von Kunst« auch zu postulieren, die Avantgarde habe die »Kunst ihres Kunstcharakters berauben" wollen (M. Hardt). Zwar stellen gerade die Manifeste die Grenze zwischen Kunst und Leben, zwischen autoreferentiellem und performativem Charakter von Texten in Frage, doch sie versuchen dies, ohne auf den Kunstanspruch ganz (oder auch nur teilweise) zu verzichten. Wenn die Avantgarde »von der Kunst aus eine neue Lebenspraxis organisieren « will (Bürger), meint dies eben nicht so sehr das Ende der Kunst als vielmehr jenes einer bestimmten Lebenspraxis - nach deren radikaler Veränderung dann in der Tat eine Selbstaufhebung der Kunst gelingen könnte, weil diese avantgardistische Kunst Teil des Lebens geworden ist.

Mit ihrer Utopie einer anderen, nicht länger vom Leben getrennten Kunst bricht die Avantgarde zu »neuen Ufern « (Adorno) auf, auch und zunächst - aus heutiger Sicht muß man feststellen: primär - für die Kunst. Die Avantgarde bewirkt mit ihren Manifesten nicht das Ende der Kunst, sie schafft letzten Endes sogar eine neue Ästhetik. Dabei verändert ihre Verweigerung von traditioneller Kommunikation zwar etablierte Wahrnehmungsweisen, doch trotz dieses ausgesprochen radikalen Bruches wird die Avantgarde von der Institution Kunst, in einem durchaus bürgerlichen Sinne, doch eingeholt, während sie sich im politischen Bereich einer Unterwerfung unter politische Programme zu widersetzen weiß - oder aber sich als Avantgarde selbst aufgibt bzw. zur Aufgabe gezwungen wird. 


\section{Die Manifeste}

Ein Blick auf die Machart der Manifeste macht die Besonderheiten avantgardistischer Kommunikation deutlich, zeigt Tradition und Traditionsbruch im Manifestantismus und läßt dabei zwei Linien bei der Proklamierung der Ismen erkennen.

Da wird zunächst auf eine wenig originell anmutende, in der Tradition des Manifestantismus des 19. Jahrhunderts stehende Weise proklamiert und postuliert. Gleich das erste Manifest, mit dem die Geburt der Avantgarde eingeläutet wird, Marinettis »Gründung und Manifest des Futurismus«, enthält elf brav durchgezählte Punkte, die vielleicht durch ihre Radikalität, Brutalität und Monomanie auffallen, nicht aber durch eine Form oder einen Stil oder eine Sprache, die diese Punkte von einer Proklamation des Symbolismus unterschiede; das Verhältnis von Postulat und Form des Manifestes bleibt konventionell. Ähnliches gilt zunächst sogar für das ebenso berühmte DadaManifest vom April 1918, das die prominentesten Vertreter von Dada Zürich und Dada Berlin unterzeichnet haben; entgegen dem geläufigen Vorurteil, Dada meine nichts anderes als Destruktion, Negation und Kommunikationsverweigerung, finden sich in diesem dadaistischen Schlüsseltext rundum positiv formulierte Forderungen, die nichts anderes im Sinn haben, als für »die besten und unerhörtesten Künstler« zumindest in nuce eine durch und durch konstruktive Ästhetik zu formulieren. Auch ein kanonisierter avantgardistischer Großtext wie das erste surrealistische Manifest von Breton operiert, trotz der Phantasie, der er an die Macht helfen will, in zumeist traditionellen Fahrwassern, etwa wenn er zur Explikation des Surrealismus-Begriffs eine auch der Form nach lexikalische Definition unternimmt, ausführlich mit Belegstellen arbeitet und eine Ahnengalerie surrealistischer Vorfahren einrichtet - ein auf den ersten Blick eher 'passatistisches`, nicht eben ’avantgardistisch` anmutendes Unterfangen; die wenigen surrealistischen Passagen oder 'Zitate ‘ belegen diesen Befund eher als daß sie aus dem Manifest einen auch der Form nach ssurrealistischen` Text machten.

Dennoch praktiziert die Avantgarde ihren Bruch auch und gerade mit der ManifesteTradition. Das deutet sich schon im ersten Manifest des Futurismus an, wenn nämlich erzählerische Passagen eingefügt werden, die dem Genre gänzlich fremd sind, dem futuristischen Manifestanten aber unerläßlich scheinen, um seinen alles umschließenden Avantgarde-Blick - »Auf dem Gipfel der Welt stehend «, wie es im Schlußsatz heißt zu bekräftigen. Deutlicher noch sprengen andere Verfahrensweisen das Genre selbst auf. Um bei dem genannten Dada-Manifest zu bleiben: Es postuliert ganz und gar positive Kunst- und Künstlerbestimmungen (und ist damit kein, wie häufig kolportiert, Anti-Kunst-Manifest); es verläßt aber den traditionellen Manifestantismus, wenn es ausdrücklich »den Dadaismus in Wort und Bild « proklamieren will, zugleich aber behauptet: „Gegen dies Manifest sein heißt, Dadaist zu sein!«. Hier ist es also die alogische Volte, die in eine zunächst positiv angelegte Proklamation die Reflexion über die Institution des Proklamierens selbst einbezieht. In anderen Texten gerade von Dada wird das auf die Spitze getrieben, so, wenn in einer bestimmten Form Forderungen erhoben werden, die vor allem die Funktion haben, das Erheben von Forderungen in eben diesen Formen zu denunzieren - weil dieser Weg der Bewußtseins- und Gesellschaftsveränderung nicht mehr gangbar erscheint; der Text »Was ist der Dadaismus und was will er in Deutschland? « zielt in diese besonders für Dada konstitutive Richtung. Deshalb ist auch das seinerzeit noch provozierend wirkende Layout vieler dadaistischer Texte unverzichtbarer Teil der Botschaft und nicht attraktives Design: Erwartungs- 
horizont und Eindeutigkeit in Sachen Manifestantismus sollen gestört, eine neue Kommunikation erprobt werden. Daß das bis zum spielerischen Umgang mit den Lettern, auch bis zum Nonsens gehen kann, bestätigt nur diese dem avantgardistischen Manifestantismus eigene Kritik an traditionellen Weisen des Manifestierens bis hin zur Kritik am Manifestieren selbst im >Anti-Manifest‘.

Gerade diese Experimental-Manifeste, in denen die Avantgarde den Troß des >Passatismus am weitesten hinter sich läßt, wollen vermeiden, daß sie ihren inhaltlichen Appellen nicht durch traditionelle Formen selbst in den Rücken fallen; beides soll performativ wirken, die Wirklichkeit verändern - wobei durchaus eine autoreferentielle Falle entstehen kann. Denn hier besteht die Gefahr, daß ein dergestalt elaboriertes Manifest unter der Hand eine eigene ästhetische Dynamik entwickelt, die dem Anspruch, den musealen Charakter des künstlerischen >Werkes zu durchbrechen, diametral zuwiderläuft und sich seinerseits mit der Aura der Einmaligkeit umgibt. Eine derartige Homologiestruktur von inhaltlicher Aussage und künstlerischer Umsetzung charakterisiert vor allem die Hochzeit der Avantgarde im Zeichen von Dada; allerdings wurde der $>$ Werk $<-$ Charakter vieler dadaistischer Manifestationen durch den operativen Einsatz ihrer Texte, der eine Aura dann doch nicht aufkommen ließ, neutralisiert. Daß es im übrigen gerade diese Experimental-Texte der radikalen Avantgarde sind, die heute die Antiquariatspreise hochtreiben, steht auf einem gesonderten Blatt.

Einen anderen Weg beschreiten die surrealistischen Manifeste, speziell die beiden Groß-Manifeste von André Breton. In Analogie zu den wissenschaftlichen Revolutionen verheißen sie eine grundsätzlich andere Welt: die Texte bedürfen also nicht mehr des auch in der Form vollzogenen Bruches mit den Normen der Gegenwart, auch wenn sie diesen - hinter der konventionell-expositorischen Form des Manifestes - zitatweise sichtbar werden lassen. Ein Vergleich zur literarischen Form der Utopie (etwa jener des in den 40er Jahren von Breton entdeckten Charles Fourier) ließe sich hier ziehen: obwohl es der Utopie doch um die alternative, die völlig andere und beste aller möglichen Welten geht, bedient sie sich doch Jahrhunderte hindurch ganz traditioneller Darstellungsformen.

Im Manifestantismus der Avantgarde lassen sich also zwei Linien erkennen, die im übrigen in je unterschiedlicher Weise Kunstwerkcharakter beanspruchen, immer jedoch in der Absicht, die Autonomie von Kunstwerken in Frage zu stellen bzw. aufzuheben. Zum einen jene - minoritären - Manifeste, die ihre Ziele in einer radikal mit traditionellen Wahrnehmungsweisen brechenden Form umsetzen, zum anderen jene zahlreicheren - Manifeste, die in der Tradition des Manifestantismus des 19. Jahrhunderts stehen, aber nicht selten dazu neigen, ansatzweise doch Neuerungen zuzulassen, wie das Beispiel der italienischen Futurismus-Manifeste verdeutlicht. Ein polemisches Durcheinanderwerfen von Punkten, also nicht svon vorne beginnen, wie Alexander Kruchonych und Kurt Schwitters es tun, verweist schon äußerlich auf das Unbehagen der Avantgarde an ihren eigenen, einsträngig formulierten, kohärent und rational argumentierenden Forderungen. $\mathrm{Da} ß$ man ansonsten aber auf alle nur denkbaren Spielarten des Manifesteschreibens stößt - vom Kurzmanifest der russischen Futuristen bis zum viele Seiten langen Manifest von Poetismus oder Surrealismus, von den reinen Lesetexten des italienischen Futurismus bis zum Bildmanifest eines Štyrzký, vom narrativen bis zum diskursiven, von der sinnstiftenden bis zur sinnverweigernden Deklaration - liegt bei einer Bewegung, die sich wie keine andere dem Manifest verschrieben hat, auf der Hand. Ein Blick auf die hier abgedruckten etwa 250 Texte 
macht Variationsbreite der Formen und Vorlieben für bestimmte Darbietungsweisen augenfällig.

\section{Internationalität}

In ihren Manifesten und Proklamationen führt die Avantgarde nicht nur vor, wie sie ihre Botschaften vermittelt; ihre Manifeste verraten auch die unglaublich engen Verflechtungen der europäischen Avantgarde. Das gilt für die Manifesteschreiber und -unterzeichner, für die Orte, an denen sie ihre Manifeste der Öffentlichkeit präsentieren, und das gilt für die Interdependenzen der Texte, die sich die Avantgarde wie Bälle zuwirft.

Allem Anschein nach existiert so etwas wie eine Internationale der Unterzeichner; es gibt Manifeste, in denen sich die Creme der europäischen Avantgarde wiederfindet, sei es im "Dadaistischen Manifest« von 1918, das von deutschen, schweizerischen, rumänischen, französischen und italienischen Dadaleuten unterzeichnet ist, sei es das französisch-italienisch-amerikanische Anti-Marinetti-Manifest "Dada hebt alles auf», sei es die surrealistische Forderung »Hands off love« oder der Internationalismus der Manifeste zum Düsseldorfer »Kongreß der internationalen fortschrittlichen Künstler « (1922), auf dem beispielsweise die lettische Avantgarde (»Gruppe Synthès«) sich erstmals vor einem größerem westeuropäischen Publikum Gehör verschaffen konnte. Das gilt nicht zuletzt für ein singuläres Manifest wie »Dichtung ist vertikal«, zu dem sich 1932 Autoren wie Hans Arp, Samuel Beckett, Carl Einstein u. a. zusammengefunden haben, oder für einen der letzten großen Aufrufe vor dem 2. Weltkrieg, André Bretons und Leo Trotzkis Forderung nach einer »freien, revolutionären Kunst«.

Die avantgardistische Vernetzung zeigt sich zudem in der Mehrprachigkeit von Texten und von Publikationsorganen - die Avantgarde ist polyglott und übersetzt sich notfalls selbst; nicht zufällig sind prominente Avantgardisten wie Ivan Goll, Vincent Huidobro oder Tristan Tzara zweisprachige Autoren. Mehrsprachige, parallele Abdrucke von Manifesten finden sich im niederländischen »De Stijl«, der seine ersten Manifeste neben der Muttersprache in einer englischen, französischen und deutschen Version herausbringt, oder im sowjetrussische LEF, der einige Aufrufe ebenfalls in deutscher und englischer Übertragung mitliefert. Marinetti hat viele der futuristischen Manifeste parallel in italienischer und französischer Version verbreiten lassen, zudem registrierte die Avantgardepresse (aus welchen Motiven auch immer) sehr genau den aktuellen Stand des Manifestantismus anderswo - noch an eher entlegenem Ort wie der Zeitschrift »Bleu« von Dada-Mantua findet sich beispielsweise 1920 (in $\mathrm{Nr}$ 2) die italienische Übertragung des 2. Manifestes von »De Stijl«.

Bekanntermaßen verlaufen gerade Dada-Veranstaltungen häufig mehrsprachigsimultan, sei es, daß gleichzeitig mehrere Texte, sei es, daß mehrere Texte gleichzeitig in verschiedenen Sprachen vorgetragen werden (oder beides). Entsprechendes gilt für andere Formen der avantgardistischen Ver-Öffentlichung. Eine Zeitschrift wie »Mécano« erscheint im niederländischen Leiden und publiziert die erstaunlichsten Texte in deutscher, französischer und niederländischer Sprache; das "Internationale Bulletin des Surrealismus« wird Mitte der 30er Jahre jeweils zweisprachig und an wechselnden Orten - in Prag (tschechisch/französisch), in Brüssel, in London (englisch/französisch) herausgegeben, entsprechend länderüberschreitend sind die Verflechtungen auch in den Erklärungen.

Wirkungen und Wechselwirkungen der avantgardistischen Programmatiken lassen 
sich anhand der Chronologie ihrer Manifeste in ganz aufschlußreicher Weise rekonstruieren. Die Druck- und Wirkungsgeschichte des 1. Manifestes von Marinetti beispielsweise ergibt folgendes: auf die Erstveröffentlichung der französischen Version im Pariser »Figaro" vom 20.2.1909 folgte die leicht modifizierte italienische Fassung im Februar/März-Heft der Mailänder »Poesia«. Im Juli 1909 präsentierte Marinetti dort bereits einen Pressespiegel über die internationale Resonanz, die vom »L'Echo de Paris« bis zu »The Sun«, von der »Frankfurter Zeitung« bis zu »El Liberal« reicht. Schon im April 1909 erscheint eine spanische Version des Manifestes im »Prometeo«, im Mai 1909 kennt man in St. Petersburg Auszüge aus der "Poesia«-Fassung des Manifestes (und Marinettis Manifeste erscheinen bereits gesammelt 1914 in einer russischen Ausgabe), bis es 1912 in deutscher Übertragung an den Berliner Litfaßsäulen aushängt.

Anhand der Kontroversen zwischen italienischem und russischen Futurismus, die spätestens bei Marinettis Rußlandreise 1914 aufbrechen (vgl. das Anti-Marinetti-Flugblatt), werden Rangeleien um das Erstgeburtsrecht in Sachen Futurismus erkennbar (in ihren Erinnerungen haben einige russische Futuristen die Datierung einschlägiger Deklarationen vorverlegt). Auch in Großbritannien kommt es anläßlich der Futurismus-Ausstellung von $1914 \mathrm{zu}$ Auseinandersetzungen zwischen Marinetti, der quasi ein Urheberrecht am futuristischen Avantgardismus reklamiert, und der englischen Vortex-Gruppe. Wichtiger sind aber die auch in der Kontroverse erkennbaren gemeinsamen Verbindungslinien des futuristischen Aufbruchs der Avantgarde in Italien und Rußland, wie die entsprechenden Vorkriegs-Manifeste ihn augenfällig machen.

Eine zusammenhängende Lektüre der Manifeste - selbst wenn sie sich, wie beispeilsweise im Falle Chlebnikovs, auf den Monat genau nicht mehr datieren lassen macht aber eines deutlich: unabhängig vom Pochen aufs Copyright läßt sich anhand der Manifeste-Chronologie sehr genau erkennen, wann und wo die Innovationsschübe erfolgt sind, wo (quasi militärisch) die Angriffslinien und die Zielobjekte der Avantgarde liegen, wie und von wem die Manifeste avantgarde-intern wahrgenommen worden sind, wer jeweils daran beteiligt war. Das erlaubt Rückschlüsse auf die Topographie der Avantgarde und ihrer Manifeste.

\section{Topographie der Manifeste}

Die Avantgarde produziert ihre Manifeste schubweise, in Wellen; ein Blick auf die Chronologie macht die quantitativen Schwerpunkte deutlich, das Länderverzeichnis zeigt zudem geographische Schübe auf; Konjunkturen,Vernetzungen und Flauten des avantgardistischen Manifestantismus gestatten Einblicke in die Werkstätten der Ismen, sie ermöglichen eine Topographie der Manifeste in all ihren Besonderheiten, die allererst noch zu schreiben ist.

Der futuristischer Aufbruch der Avantgarde vollzieht sich im musealen Italien, wo der Alp der Vergangenheit für die junge oppositionelle Intelligenz offenbar besonders drückend war; ihrer Gier nach >Modernisierung` des Lebens, den neuesten Maschinen, nach Geschwindigkeit stand wie sonst nirgendwo die passatistische Macht eines Kulturerbes entgegen, dessen Reichtum die futuristischen Zerstörungsphantasien besonders beflügelt hat. So wird das "passatistische Venedig«, dieser Lieblingsort der Décadence, zur futuristischen Zielscheibe, und der futuristische Aufbruch reklamiert in seinem Modernisierungskonzept von Anfang an nicht allein ästhetische, sondern auch 
massive politisch-gesellschaftliche Veränderungen, zu deren Trägerin die Avantgarde sich selbst beruft.

Dem avantgardistischen Großmanager Marinetti ist es gelungen, seine Bewegung national und international bekannt zu machen; das war sicher nur möglich, weil es auch anderswo vergleichbare Erwartungen, eine ähnliche Bereitschaft zur radikalen Kunstkritik gab, ohne die Marinetti trotz seines Organisationstalents nicht diese Resonanz gehabt hätte.

In Deutschland finden sich seit 1910 in Berlin und München die Frühexpressionisten zusammen; sie plagt zwar auch ein abgrundtiefes Unbehagen an der alten Kultur ihrer Väter, in ihrem Aufbruch wollen sie aber die Kunst zu erneuern, nicht liquidieren. In ihren Gedichten suchen und finden sie unerhört neue Bilder, neue Metaphern - sie wollen aber keineswegs etwas anderes als 'Werke‘, als 'Kunst‘ schaffen. Insofern ist ihr 'Ismus «, der gegen eine bestimmte naturalistische und impressionistische Kunst opponiert, von den Ismen der Avantgarde entfernt, ist die spezifisch avantgardistische Vorstellung von einer Überführung von Kunst in Leben dem deutschen Expressionismus weithin fremd - der frühe deutsche Beitrag zur Avantgarde spiegelt sich zunächst in der eher skeptischen, von Berührungsängsten geprägten Auseinandersetzung mit der futuristischen Offensive vor dem 1 . Weltkrieg wider. Anders als beispielsweise in Rußland, wo mit dem Jahr 1913 schon ein Gipfel der avantgardistischen Manifest- und Kunstproduktion erreicht ist, während im für die Bildende Kunst zentralen Frankreich und in der künstlerisch-literarischen Pariser Szene der Manifestantismus fast ausschließlich die Sache eher peripherer Protagonisten ist (Apollinaires "Futuristische Antitradition " kann durchaus in diesem Sinne gelesen werden).

Mit der rapide einsetzenden Politisierung des Expressionismus während des Krieges und der Explosion von Dada in Zürich erklimmt - zunächst im schweizer Exil, dann in Berlin und anderen Großstädten - die deutschsprachige Szene rasch Gipfelpunkte der Avantgarde. Die gescheiterte Novemberrevolution und ihre Folgen führen zur Ausdifferenzierung eines 'deutschen Sonderweges in Sachen Avantgarde. Ein Teil des hochpolitisierten Berliner Dada nähert sich der 'politischen Avantgarde`, zunächst noch mit dem Versuch, dabei Positionen der ästhetischen Avantgarde bewahren zu können (Grosz, Heartfield, Jung u.a.). Nach den Verwicklungen während der revolutionären Nachkriegskrise wird sich dann Mitte der 20er Jahre ein Stamm von linken Intellektuellen im näheren Umfeld der KPD zusammenfinden und sich um eine revolutionäre Literatur und Kunst bemühen, bei der Avantgarde-Positionen zwar noch diskutiert werden, die aber prinzipiell im Zeichen von Realismus-Doktrinen stehen. Ein anderer Flügel, zumal in der Bildenden Kunst, formiert sich zu dieser Zeit in der Neuen Sachlichkeit, die sich auf den Boden der Weimarer Tatsachen stellt: in beiden Fällen ein Abbruch avantgardistischer Positionen, wie er so anderswo nicht begegnet. Der eigentliche Kern der deutschen Avantgarde ist recht klein geworden: Franz Pfemferts "Aktion" hat sich schon zu Zeiten der Novemberrevolution von Kunst und Literatur weitgehend verabschiedet; der "Sturm " um Herwarth Walden kann an die Resonanz, die er vor allem in den 10er Jahren erfahren hat, nicht mehr anknüpfen, macht sich aber nicht zuletzt dadurch verdient, daß er das deutsche Publikum zumal über die ost- und südosteuropäische Avantgarde informiert. So sind es die großen Einzelgänger wie Raoul Hausmann oder Kurt Schwitters, in der Theaterpraxis später vielleicht noch Oskar Schlemmer mit der Bauhaus-Bühne, die in wechselnden Konstellationen an avantgardistischen Prinzipien weiterarbeiten. Eine so schillernde Figur wie Franz Jung verläßt die 
Literatur und arbeitet für mehrere Jahre als Wirtschaftsexperte in Sowjetrußland, und auch ein so brillanter Kopf wie Carl Einstein entzieht sich der deutschen Szene und geht frühzeitig nach Paris; der von ihm 1925 zusammen mit Paul Westheim bei Kiepenheuer herausgebene große Avantgarde-Almanach "Europa« mit europäischen Zeugnissen aus "Malerei, Literatur, Musik, Architektur, Plastik, Bühne, Film, Mode« signalisiert übrigens, wie sehr das Genre Manifest zu diesem Zeitpunkt - zumindest in Deutschland an Gewicht schon verloren hat: als einzigen Programmtext wird Fernand Légers »Sehr aktuell sein« aufgenommen. - Wenn der Reigen der deutschsprachigen Proklamationen 1924 mit "Konsequente Dichtung" von Schwitters endet, so macht das die deutsche Sonderentwicklung sinnfällig: in diesem Jahr konstituiert sich in Frankreich mit dem Surrealismus ein neuer großer Avantgardeschub, in dessen Zeichen die europäische Avantgarde der späteren 20er und der 30er Jahre stehen wird, der aber für die deutschen Verhältnisse, wie schon Benjamin resümiert, keine größeren Wirkungen zeitigt.

Politisierung und Polarisierung der Avantgarde in Deutschland waren nicht zuletzt Ergebnis der besonderen politischen Konstellation 1918/19; vergleichbares gilt für Rußland: die futuristische Vorhut sieht in der politischen Avantgarde der Bolschewiki ihre Orientierung, Avantgarde und Oktoberrevolution gehen im Zeichen nachrevolutionärer, zumindest relativer Offenheit der Kunstszene ein Stück gemeinsamen Weges. Nicht zuletzt Trotzkis Ausführungen über den Futurismus (in "Literatur und Revolution«, 1924) oder das LEF-Manifest an die "Lebensformer" machen aber auch die Grenzen dieser Allianz deutlich; Revolutionskunst wird zunehmend Kunst des Realismus, eines platten Realismus zudem. Mit OBERIU 1928 erlebt die Avantgarde in der Sowjetunion ihren Schwanengesang. - Die übrige slawische Avantgarde hat ihren Reichtum, der für die deutsche Rezeption und die deutschsprachige Avantgarde-Forschung allererst noch zugänglich gemacht werden muß, in allen nationalen Literaturen unter Beweis gestellt. Kurz und heftig im neugegründeten Polen, das von Warschau bis Krakau 1921 eine rasante Futurismuswelle durchlief, in dem aber auch Formismus und Konstruktivismus wichtige Beiträge zur Avantgarde lieferten. Dauerhafter entfaltete sich die Avantgarde der Tschechoslowakei, wo sich mit Devetsil, Poetismus und schließlich Surrealismus, aber auch mit dem Kubismus Eigenständigkeit und Internationalität der Avantgarde zeigt. Hier wird der 'Purismus` von Ozenfant/Jeanneret wahrgenommen, und mit Karel Teige und Víteslav Nezval begegnen zwei Autoren, deren Programmatik und deren 'Werk « in den jeweiligen ästhetischen und politischen Verwicklungen ein getreues Bild von Gesamtentwicklungen der europäischen Avantgarde geben. Das gilt nicht zuletzt für den Bruch innerhalb des tschechischen Surrealismus während der 30er Jahre, der sich anläßlich der Frage des Verhältnisses zum Kommunismus moskauer Prägung vollzieht. - Die serbokroatische Avantgarde durchläuft die Phasen von Expressionismus, Dada und Surrealismus und kreiert mit dem Zenitismus, dem schon Ivan Goll das Wort geredet hatte, einen eigenen Ismus, den wiederum im fernen niederländischen Groningen der einsame Avantgardist Hendrik Werkman in seiner im Handbetrieb hergestellten Zeitschrift "The Next Call« sehr genau beobachtet. Der mehsprachige "Tank « in Lubljana verfolgt und übersetzt die verbliebene deutschsprachige Szene des »Sturm«, Kurt Schwitters vor allem. Die ungarische Avantgarde schließlich, nach Zerschlagung der Räterepublik im österreichischen Exil, macht ihre mitemigrierte Zeitschrift »MA in Wien durch eigene Manifeste und durch Übersetzungen zu einer avantgardistsichen Drehscheibe. - Weshalb die Avantgarde in Skandinavien kaum Fuß faßte und mit den finnischen »Feuerträgern« erst relativ spät und auch eher verhaltene Avantgarde-Positionen begegenen, bedürfte wohl noch genauerer Analysen. 
In der Romania nimmt die Dominanz der italienischen Avantgarde in dem Maße ab, als diese sich europäisch weitgehend durchgesetzt hat und in Italien selbst der Mussolini-Faschismus den Futurismus teils toleriert, teils als Staatskunst sanktioniert; in seinem »Brief über den italienischen Futurismus« an Trotzki schreibt Antonio Gramsci 1922, daß die futuristische Bewegung in Italien »nach dem Kriege ihre charakteristischen Merkmale völlig verloren« habe. Sicher verläßt der sog. "Zweite Futurismus« in Italien (seit der Mussolini-Herrschaft 1922) das Terrain der Avantgarde.

Dank der gesamteuropäischen Strategie Marinettis wird der Futurismus in den romanischen Ländern zwar wahrgenommen - so greift Ramón Gómez de la Serna (»Tristán«) mit seiner »Futuristischen Proklamation an die Spanier« schon 1910 Marinettis Losungen auf, und Valentine de Saint-Point antwortet dem Führer des Futurismus 1912, mehr als ein Jahr vor Apollinaire, mit dem "Manifest der futuristischen Frau«. Insgesamt freilich bleibt die Wirkung des Futurismus begrenzt: die avantgarde-nahen Strömungen in Frankreich und Spanien gehen andere, literarischere Wege und die bildende Kunst, zumal in Paris, nimmt die italienische Bewegung kaum zur Kenntnis. Zwar macht sich der Futurismus während des Ersten Weltkrieges relativ spät, aber spektakulär in Portugal bemerkbar, doch selbst Fernando Pessoas Manifeste von 1915 (»Intersektionistisches Manifest«) und 1917 (»Ultimatum«) vermögen keine bleibende Wirkung zu entfalten.

Gegen Ende des Krieges erreicht die Avantgarde dank der dadaistischen Aktivitäten Paris. In Spanien, genauer in Barcelona, gibt es schon während der letzten Kriegsjahre eine aktive und attraktive avantgardistische »Kolonie « um Francis Picabia und Gabrielle Buffet, doch zur gleichen Zeit entwickelt sich dort, bis zum Dalí der späten 20er Jahre, und in Madrid eine eigene und eigenständige Avantgarde. In Madrid lanciert der Chilene Vicente Huidobro, aus Paris kommend, Kreationismus und Ultraismus, die Tristan Tzara auch für seine Bewegung reklamiert - später dann verfolgen die Autoren der 27er Generation die Entwicklung der europäischen Avantgarde aus einer sichtlich auf Unabhängigkeit bedachten Distanz. - Über Jorge Luis Borges, der 1921 nach Argentinien zurückkehrt, erreicht der Ultraismus Lateinamerika, doch als dieser mit anderen das ultraistische »Prisma« an die Mauern von Buenos Aires anschlägt, läßt Manuel Maples Arce in Mexiko schon die futuristisch-dadaistische "Estridentistische Verdichtung « verteilen, und bald reagieren Schriftsteller und Künstler fast aller lateinamarikanischen Länder mit ihren Manifesten. Ohne die Rolle von Vermittlern, wie den Europareisenden Borges, Huidobro oder Mariátegui oder des so wichtigen Spaniers Guillermo de Torre unterschätzen zu wollen, gewinnt die lateinamerikanische Avantgarde, gerade dank ihrer zahlreichen Manifeste, binnen kurzer Zeit ein eigenes Profil, nicht zuletzt in der Verbindung von nationaler Identität und Ablehnung des nordamerikanischen, aber zunehmend auch europäischen Einflusses.

In Paris entzünden Anfang der 20er Jahre Tristan Tzara, der aus den USA zurückgekehrte Francis Picabia und die späteren Surrealisten wahre Feuerwerke von Manifesten, Proklamationen, Happenings und Provokationen - äußerst phantasiereiche Formen des Manifestantismus, die sich in dieser Weise aber auf Dauer totlaufen; im Herbst 1924 läutet dann André Breton mit seinem »Manifest des Surrealismus« die letzte große Avantgarde-Periode ein. - Der Surrealismus zeigt sich anfangs an der Gründung von Filialen desinteressiert. Zwar gibt es von Beginn an surrealistische Gruppen im französischsprachigen Belgien, doch, von einem spezifischen Surrealismus im Umkreis der 27er Generation in Spanien abgesehen, manifestiert sich der internationale Charakter in 
der Zusammensetzung der Pariser Gruppe selbst. Erst in den 30er Jahren entstehen surrealistische Gruppen in der Tschechoslowakei, in England und anderswo; während sich aber die Pariser Gruppe in ihrer Zusammensetzung, ihrer Zusammenarbeit mit anderen und den Anlässen für ihre Manifeste immer mehr internationalisiert, zieht die politische Entwicklung in Europa einer geographischen Ausdehnung immer engere Grenzen.

So läßt die Topographie des Manifestantismus Konjunkturen und Leerstellen hervortreten, dabei spielen politische Phänomene ebenso eine Rolle wie Besonderheiten der jeweiligen künstlerisch-literarischen Entwicklung. Diese Topographie verdeutlicht, wo sich zu welchem Zeitpunkt Zentren avantgardistischer Aktivitäten bilden und illustriert in ihrer geographischen Ausfächerung, in welchem Ausmaß der Manifestantismus während dreier Jahrzehnte Europa und Lateinamerika erfaßt.

\section{Signatur der Manifeste}

Mit dem Angriff auf die Institution Kunst geht eine radikale Veränderung des Kunstund Werkbegriffes einher. Die Manifeste werden zwar, in noch höherem Maße als jene des 19. Jahrhunderts, durchaus auch als literarische Werke konzipiert; erinnert sei nur an das in Tzaras Theaterstück »Première Aventure céleste de M. Antipyrine« integrierte "Manifest des Herrn Antipyrine«, eine der Gründungsurkunden des Dadaismus. Sie verzichten jedoch bewußt darauf, als sWerk « sich selbst zu genügen, geschweige denn, daß sie autoreferentiellen Charakter beanspruchen wollen - diesen Abschied vom Kunstwerk und seiner Aura reklamiert die Avantgarde für Kunst und Literatur insgesamt.

Der Avantgarde gelingt es, die Kategorie des Kunstwerkes völlig zu verändern. Das 'Manifest‘, das >Werk` der Avantgarde insgesamt zielt nicht mehr allein darauf, neue Inhalte $\mathrm{zu}$ formulieren und zu propagieren, beide praktizieren vielmehr die Verweigerung von Sinn, von Sinnstiftung im traditionellen Verständnis und organisieren damit den Bruch mit der Kommunikation - zugunsten neuer Kommunikationsweisen. Dabei zieht die Avantgarde nicht nur alle Register, um zu diesem Bruch aufzurufen; sie will zudem aufzeigen, wie die Erkundungsfahrt organisiert werden muß, die zu jenen neuen Ufern führt, an denen sie ihr Projekt realisieren könnte. Die Manifeste sind die Wegweiser. Aus den Gefilden des Passatismus, der traditionellen Kunst, der >Werk «-Ästhetik führen sie heraus und beanspruchen der Tendenz nach, diese Terrains auch schon verlassen zu haben.

Produktion und Rezeption der Avantgarde-Manifeste tragen solchen Prinzipien des ,Projektes Avantgarde‘ zumindest ansatzweise Rechnung. - Inwieweit die avantgardistische Kunstproduktion den Bereich der bürgerlichen sInstitution Kunst ‘ definitiv zu verlassen vermochte, sei dahingestellt; zumindest gibt es deutliche Hinweise, die den radikalen Bruch bezeugen. Der Kollektivcharakter von futuristischen Soireen und Serate, dadaistischen Aktionen und Happenings oder surrealistischen Tribunalen deutet darauf, daß das Prinzip der Aufhebung einer Trennung von Kunst und Lebenspraxis zumindest hier ansatzweise realisiert wurde. Die besonderen Produktions- und Rezeptionsweisen derartiger Avantgarde-Aktionen weisen auf den Manifestantismus zurück, der dafür als das am besten geeignete Genre die Leitlinie abgibt. Als bewußt performativ gedachte Texte bilden die Manifeste einen ausgezeichneten Kronzeugen für die Absichten der Avantgarde. Selbst wenn nicht alle Kunstsparten aufgrund bestimmter 
Eigenheiten der Gattungen gleichermaßen Manifestantismus betreiben, so bleibt dies Genre dennoch Ausgangs- und Endpunkt der Avantgarde-Intentionen.

Das zeigt sich bei der Manifest-Produktion auch in einer auffälligen Akzentverschiebung vom Individuum zum Kollektiv. Trotz der großen, von einzelnen Autoren signierten Manifeste, angefangen bei Marinettis beispielgebender Ouvertüre, stellt sich die Frage, ob es bei diesem Genre Einzelwerke im traditionellen Sinne, als allein von Einzelnen zu verantwortende autonome Texte überhaupt noch geben kann: Ist nicht auch das individuelle Manifest immer das Produkt eines Gruppenprozesses, oder beabsichtigt es nicht zumindest, mit seiner Publikation einen solchen in Gang zu setzen? Unter diesem Aspekt wäre die kollektive Manifest-Produktion bzw. das Ziel, einen kollektiven Prozeß in Gang zu setzen oder zu befördern, schon beinahe eine notwendige Bedingung für die Zuordnung von Texten und Autoren zur Avantgarde.

Sicher gilt das idealiter; Unterschriften-Ensembles sind häufig eher zufällig zustandegekommen, Kollektivtexte lassen individuelle Handschriften erkennen. Dennoch macht gerade die surrealistische Bewegung an zahlreichen Beispielen deutlich, welch hohen Stellenwert der kollektive Produktionsprozeß für die Avantgarde-Gruppe hat. Der avantgardistische Künstler und Schriftsteller muß, vor allem was ausgesprochen individuelle Texte angeht, die von der Gruppe akzeptierten und definierten Prinzipien respektieren. Selbst noch bei solchen Manifesten, die wie jene von Antonin Artaud gegen den Legitimationsdruck der Gruppe geschrieben werden, bildet deren Kollektiv die Definitionsinstanz.

Diese Priorität der kollektiven Produktion bedingt eine weitere Dimension des Manifestantismus. Schon der Futurismus erwartet und fördert die Gründung von `Filialen`, die sich mit Manifesten, zuweilen unter Anleitung des Führers (Marinetti-Nevinson oder Marinetti-Mac Delmarle), in die Bewegung einordnen; auch die inner-avantgardistischen Reaktionen und Gegen-Manifeste, schon beim Futurismus, sehen sich wie z. B. der englische Vortex-Kreis gezwungen, alternative Auffassungen kollektiv zu manifestieren. Wenn Dada eine große Zahl an individuell signierten Texten kennt, so führen die Rezeptionsbedingungen und das gemeinsame Ziel - sei es im Cabaret Voltaire oder das bei Spektakeln in Berlin oder Paris deklamierte Manifest - zur gemeinsamen Verantwortung aller Beteiligten gegenüber dem jeweiligen Text, wie die 23 DadaManifeste in der Avantgarde-Zeitschrift "Littérature« im Mai 1920 beispielhaft belegen. Mit dem Surrealismus erreicht unter der Ägide Bretons eine derartige kollektive Verantwortung einschließlich der damit verbundenen rigiden Rechtfertigungsmechanismen einen Höhepunkt. Die gemeinsamen Sitzungen skontrollieren ‘, inwieweit Publikationen und Aktivitäten den gemeinsamen Proklamationen entsprechen, und im Medium des Manifestes werden die Prinzipien interpretiert, fortgeschrieben, aktualisiert. Insofern geben die langen Unterschriftenlisten der surrealistischen Manifeste - wie jene ihrer Gegner - getreulich die jeweilige Situation der Gruppe wieder.

Kann ein Manifest zugleich die Handschrift eines Einzelverfassers tragen und dennoch Ergebnis und Ausdruck eines Gruppenprozesses sein, so erweist es sich erneut als optimales Genre der Avantgarde, für eine gruppenidentitätsstiftende Funktion, die den ungestümen Gebrauch erklärt, den die Avantgarde vom Manifest macht. Das hat freilich auch zur Folge, daß sich das >Projekt Avantgarde` am deutlichsten und umfassendsten an den Manifesten festmachen läßt.

Nun liegt der Gedanke nahe, gerade anhand der Manifeste Bilanz zu ziehen: was denn aus dem großen Projekt der historischen Avantgarde, wie es sich im Manifestantismus 
äußert, geworden ist, wie es sich hat realisieren lassen. Es gälte also, Anspruch und Wirklichkeit, Traum und Tat, Utopie und Realität zu vermessen - auch deshalb, um von den Realisierungsversuchen her erneut eine Gesamtperspektive auf Einheitlichkeit und innere Divergenz der Avantgarde eröffnen zu können. Umgekehrt bietet der Blick auf die Programmatiken wichtige Erklärungungszugänge für die avantgardistische Kunstpraxis, ohne daß deshalb gleich mit der Elle der Manifeste auch gemessen werden müßte. Tatsächlich lassen sich Lautgedicht, automatisches Schreiben oder Praktiken des Avantgarde-Theaters besser und genauer wahrnehmen, wenn man die diesbezüglichen Manifeste des italienischen und russischen Futurismus oder des Surrealismus in Frankreich berücksichtigt. Zudem werden die Ziele mancher Ismen eher durch ihre Proklamationen erkennbar als in ihrer Kunstpraxis jenseits der Manifeste - oder sie existieren gar allein im Manifest. Umgekehrt wird man in der Praxis der Avantgarde, mißt man sie an ihren vollmundigen Verheißungen, Defizite, nicht eingelöste Versprechungen auch in diesem Feld konstatieren können.

Nun ist es sicher sinnvoll, Anspruch und Einlösung dieses Anspruches zu konfrontieren. Daß die historische Avantgarde mit der Optik einer selbsternannten >Vorhut eine derartige Betrachtungsweise selbst herausgefordert hat, machen die Manifeste - die Manifeste als Einzeltexte wie auch der Manifestantismus in toto - überdeutlich. Insofern liest sich die Chronologie der Manifeste auch wie eine Abfolge von Führungsansprüchen und Überbietungszwängen, die oft genug, so scheint es, ohne Verbindlichkeit im Ästhetischen oder gar Politischen geblieben sind. Dies wäre ein Zugang, das sprichwörtliche 'Scheitern` der Avantgarde von ihren eigenen Ansprüchen her zu begründen, von Postulaten, die nur partiell oder gar nicht eingelöst worden sind. Dieser Weg mag sicher Attitüden eines Führunsganspruches entzaubern, der als das letzte Aufbäumen des Künstlers in der bürgerlichen Gesellschaft verstanden werden kann - einer Gesellschaft, die Kunst und Künstler schon längst keinen angemessenen Ort mehr zuzuweisen vermag. Seinerzeit erkannte Baudelaire in der Figur des Dandy »den letzten Ausbruch von Heroismus in den Niedergangsepochen « und suchte so den Dandy zu legitimieren; die avantgardistische Selbstnobilitierung zur Vorhut schlechtweg ließe sich als ein vergleichbares Aufbäumen gegen den Verfall der Kunst und die wachsende Bedeutungslosigkeit der Künstler in der spätbürgerlichen Gesellschaft sehen. Aber das avantgardistische Potential ist damit, so scheint es, noch nicht erschöpft.

Dem >Projekt Avantgarde، oder einer Utopie vorzuhalten, sie ließen sich ja doch nicht verwirklichen, den Utopieschreiber oder den Avantgardisten zu fragen, wo denn sein Nicht-Ort läge bzw. die neue Lebenspraxis zu verorten wäre, scheint ebenso unsinnig wie auf der anderen Seite der Verweis, um die genauen Wege in das Anderswo gehe es prinzipiell nicht. Der Sprengsatz einer Utopie liegt nicht im fernen Gefilde, sondern gerade in der Nähe, in der Kritik der Gegenwart, der sie die Alternative aufzeigt. Analog ließe sich für die Avantgarde festhalten, daß ihr Manifestantismus dann doch mehr ist als allein die Keimzelle einer neuen Ästhetik, aber auch mehr als ein verantwortungsloser Utopismus. Im Manifestantismus realisiert sich das 'Projekt Avantgarde‘ zu einem guten Stück selbst: indem es, auch um den Preis des Scheiterns, Alternativen zu den bestehenden Systemen in Kunst und Gesellschaft vorführt. 


\section{Manifestantismus und ' historische Avantgardes}

Die Einheit des Manifestantismus gründet in der Utopie der Ganzheitsentwürfe. In dieser Hinsicht beansprucht die Avantgarde 'Totalität‘, sowohl im Verhältnis von Kunst und Leben als auch bei der radikal zu verändernden Gesellschaft. Die Avantgarde bestreitet nicht nur aller traditionellen Kunst die Existenzberechtigung, sondern auch der Gesellschaft, in der diese Kunst ihren Ort hat. Nicht ohne Mißtrauen hat schon Trotzki bemerkt, daß der Futurismus »sich nicht auf den Rahmen der künstlerischen Form beschränkte, sondern von Anfang an [...] sich mit der politischen und gesellschaftlichen Ordnung in Verbindung brachte«. Die großen Manifeste des Futurismus, Dadaismus oder Surrealismus lassen an diesem im Wortsinne radikalen Ansatz keinen Zweifel.

Totalität im Sinne einer radikalen Veränderung von Kunst und Leben heißt jedoch nicht Totalitarismus; gerade anhand der Manifeste läßt sich überprüfen, ob von sich aus die Avantgarde zu Konzepten führt, die totalitäre Züge trägt. Zwar weist die Avantgarde in ihrer Teleologie durchaus Analogien zu anderen, politisch radikalen Positionen auf, sie entwickelt ihre Standpunkte aber, wie die Manifeste zeigen, aus sich selbst heraus. Allenfalls punktuell kann sie mit anderen radikalen Entwürfen, anderen >Vorhuten kooperieren, wie auf der Linken und der Rechten geschehen. Hier gilt: entweder, die Avantgarde gibt sich selbst auf, wie der »Zweite Futurismus « es im Italien Mussolinis tut, oder die sästhetische "Avantgarde bricht mit dem Machtanspruch der spolitischen" Avantgarde wie beim Surrealismus angesichts des Stalinismus in den 30er Jahren. Umgekehrt geht - wie im Sowjetrußland der 20er Jahre - die spolitische Avantgarde daran, der ästhetischen Vorhut den Garaus zu machen, weil auf Dauer beide Avantgarden nicht koexistieren können und weil die realistische Repräsentationskunst des Stalinismus keine Avantgarde-Konzepte verkraften kann. Der Nationalsozialismus in Deutschland schließlich subsumiert die Avantgarde mit der Moderne insgesamt unter die »Entartete Kunst« und verjagt und vernichtet sie, hierin mit dem italienischen Faschismus uneins, wie auch die Auseinandersetzungen um Marinettis Berlin-Besuch 1934 zeigen. - Wie unbegründet gerade der Totalitarismusvorwurf ist, der heutzutage von "Avantgarde und Kommunismus als den monströsen Dogmen unseres Jahrhunderts« reden läßt, belegen die Manifeste sehr genau.

In ihren Manifesten bekennt die Avantgarde Farbe. Was bleibt, ist die unglaubliche Radikalität und Phantasie einer Bewegung, die immer wieder demonstriert hat, wie 'Kunst` im frühen 20. Jahrhundert aufzusprengen und bis an welche Grenzen sie zu treiben ist. Wenn die Avantgarde sscheitert<, so nicht zuletzt deshalb, weil sie die Möglichkeiten der Kunst, zu einer befreiten Lebenspraxis zu führen, überschätzt hat und die bürgerliche Gesellschaft in ihrer Potenz, eine derartige Bewegung zu neutralisieren, zu domestizieren, zu vereinnahmen - hoffnungslos unterschätzt hat. Nicht nur vom 'Scheitern`, sondern vom >Projekt Avantgarde` zeugen allererst die Manifeste der Avantgarde.

Der vorliegende Band präsentiert über 250 Manifeste und Proklamationen aus fast 20 europäischen Ländern; wenn Lateinamerika (erstmals in deutscher Übersetzung überhaupt) en bloc einbezogen ist, so nicht in eurozentristischer Vereinnahmung, sondern 
wegen seiner anfänglich engen Verknüpfungen mit der spanisch-portugiesischen Avantgarde. - Ein sehr großer Teil der Texte wird hier erstmals in deutscher Sprache vorgestellt - die hohe Zahl von Original- und Erstübersetzungen (nahezu die Hälfte der nicht-deutschsprachigen Manifeste) verdeutlicht, daß in der Avantgardeforschung, der nationalphilologischen wie der komparatistischen, noch einiges $\mathrm{zu}$ tun ist, will man sowohl den internationalen Verflechtungen der Avantgarde als auch dem Genre des Manifestes, das wie kein anderes die Avantgarde bestimmt hat, gerecht werden. Die Originalübersetzungen aus dem Bulgarischen, Finnischen, Flämischen, Georgischen, Katalanischen, Polnischen, Portugiesischen, Spanischen und Ungarischen machen entlegenere Manifeste zugänglich, aber auch aus dem Englischen, Französischen und Italienischen und Russischen war trotz vorliegender Anthologien eine stattliche Zahl von Manifesten und Proklamationen erstmals zu übertragen, um eine vertretbare Auswahl treffen zu können.

Die strikt chronologische Anordnung der Manifeste - als Alternative zur problematischen Ordnung nach Ismen, Ländern oder Autoren - soll Aufklärung geben über Positionen, Innovationen, Wirkungen, Zentren, Schauplätze, Namen, über die Ismen und ihre Abfolge, über nationale Besonderheiten und Verschiebungen sowie länderübergreifende, das >Projekt Avantgarde` insgesamt einigende Positionen. Dabei ging es ausdrücklich darum, nicht allein die avantgardistische Prominenz zu Worte kommen zu lassen, sondern auch als eher peripher oder marginal eingestufte oder völlig unbekannte Autoren und Strömungen zumal der skleineren ‘ Länder zu dokumentieren.

Berücksichtigt wurden neben der avantgardistischen Domäne, der Literatur, auch die übrigen Kunstsparten, die Bildende Kunst vor allem, aber auch die Architektur, die Musik, das Theater, der Film - sowie die anderen Lebensbereiche, denen die Avantgarde sich zuwendet, einschließlich der Politik.

Über die Auswahl läßt sich, wie bei jeder Anthologie, streiten; sie war zunächst bestimmt durch den vorgegebenen Seitenumfang - unschwer ließen sich weitere gleichstarke Bände mit Manifesten der Avantgarde füllen. Bei der Auswahl wurde berücksichtigt, daß wichtige Manifeste zumal des italienischen Futurismus und des französischen Surrealismus in deutschsprachigen Sammelbänden vorliegen; auch russische Texte finden sich, häufig in Aussstellungskatalogen verstreut, in deutschen Übersetzungen. Unausbleibliche Kürzungen sind hier womöglich nicht ganz so schmerzlich. Darüberhinaus ging es darum, unbekannte Texte zugänglich zu machen, um das Bild der Ismen zu konturieren und auszudifferenzieren. Daß dabei auch der Begriff »Manifest « (und der Terminus »Proklamation«) der Interpretation bedurfte, liegt auf der Hand; es ließe sich wohl eine Art Gradmesser des >Manifestantischen<, des >Proklamatorischen` erstellen - angefangen vom sidealtypischen` Manifest bis zum Text mit einem gerade noch erkennbar sproklamatorischen`Charakter. Allerdings scheinen Definitionen hier kompliziert und nicht in jedem Fall für die Textauswahl ergiebig - maßgeblich für die Aufnahme eines Textes waren hier zudem Kriterien wie seine Repräsentativität für eine Strömung oder auch ein Land. Insgesamt scheint es zu früh, eine Theorie des avantgardistischen Manifestes, die von den eingangs genannten zwei Linien in den Avantgarde-Manifesten ausgehen könnte, zu formulieren, und wohl auch, schon eine Geschichte des avantgardistischen Manifestantismus zu schreiben. Die hier vorgelegte Manifeste-Sammlung könnte aber dafür den Weg bereiten und zudem für die anhaltenden Debatten über Avantgarde, Moderne, Postmoderne ein solideres Fundament geben, als dies häufig erkennbar ist. Zumindest präsentiert diese Anthologie in 
einem bisher nicht gekannten Umfang die historische Avantgarde in der ureigenen Art ihrer Selbstdarstellung, in ihrem Medium par excellence: dem Manifest.

Es sei allen gedankt, die uns bei unserer Arbeit geholfen haben: vorab allen Übersetzerinnen und Übersetzern sowie Isabel Asholt (Berlin), Constanze Baethge (Paris), Hubert van den Berg (Leiderdorp/Amsterdam), Christiane Hesemann (Osnabrück), Rainer Hess (Freiburg), Helga Karrenbrock (Osnabrück/Essen), Giovanni Lista (Paris), Peter Ludewig (Berlin), Siegrid Markmann (Osnabrück), Fritz und Sieglinde Mierau (Berlin), Bernd E. Scholz (Marburg), Danielle Thor (Osnabrück), Harald WentzlaffEggebert (Jena), sowie, avant tout, Bernd Lutz vom Metzler-Verlag.

Wolfgang Asholt

Walter Fähnders 